\title{
Discussion on polycrystals over single crystals for optical devices
}

Mythili Prakasam and Alain Largeteau

CNRS, Université de Bordeaux, ICMCB, 87 av. du Dr. A. Schweitzer, Pessac, F-33608, France

Phone: +33 (0)5 400026 60/ Fax: +33 (0)5 40002761

\begin{abstract}
Conventional transparent materials have a strong absorption in the infrared region making them unsuitable in this spectral range. Crystal growth processes are usually very time-consuming and needs sophisticated / expensive machines. Polycrystalline nature of the ceramics is prone to diffusing light, which primarily arises from residual pores, grain boundaries, secondary phases and birefringency (anisotropic materials). Rapid sintering techniques such as Spark Plasma Sintering (SPS) helps in obtaining maximum densification in short duration of time at comparatively lesser sintering temperatures in comparison to other classical sintering. Simultaneous application of pressure and the help of Joules heating aids in avoiding Ostwald's ripening. Most of the current transparent ceramics are limited only to cubic materials, currently extended to non-cubic materials as well though in early stages. Conventionally optically transparent ceramics are often fabricated by either hot-isostatic pressing (HIP), or hot pressing (HP) or vacuum sintering at very high temperatures using ultrapure ultrafine powders. We have demonstrated successfully the fabrication of transparent ceramics of both cubic and non-cubic crystal structured materials by spark plasma sintering (SPS) for materials without any additives/ sintering aids. The fabrication methodology their possible device applications in comparison to single crystals will be discussed in detail.
\end{abstract}

\section{INTRODUCTION}

Upon indication of transparent materials, initially focus was only on single crystals or glasses. With the recent technological advances in sintering technology and nanopowders fabrication, it is possible to obtain a dense ceramic that is transparent. It is possible to master the sintering parameters and realize transparent ceramics with properties similar to single crystals. Transparent ceramics processing with nanosized ceramic powders and advanced densification technology provides an alternative approach to overcome the disadvantages / limits of conventional single-crystal growth process. Single crystals fabrication is time consuming, complicated and expensive; usually the size of the sample is predetermined by the crystal structure of the material. Nanopowders improve mechanical properties of ceramics and lowers sintering temperature. In order to have practical applications, the fabricated ceramics should have certain thickness to be implemented for device applications. In case of increase in thickness in particular for non-cubic materials, the transparency of ceramics will decrease. Birefringence is another criterion, which contributes to light scattering in case of non-cubic crystallites. In the case of cubic ceramics, birefringence does not affect the transparency however at equal relative density and grain size, the hardness decreases. The hardness also decreases whenever the grain sizes increases $>5 \mu \mathrm{m}$, which increases during high sintering temperatures.

In order to consolidate a material with a density close to theoretical and a grain size as small as possible, various techniques have been developed that increase density and decrease grain size. Of these, widely used methods involves fast heating, high pressure, and addition of various agents that accelerate shrinkage and inhibit grain growth. These include the use of grain growth inhibitors in solid solution or forming discrete second phases, high-pressure densification, 
spark-plasma sintering and related techniques, shock densification, high-frequency induction heating and magnetic pulse compaction ${ }^{1}$.

The conventional polycrystalline ceramic materials have many light-scattering centers: a refractive index modulation and optical diffusion around the grain boundary; index changes by inclusions or pores; segregations of the different phases; birefringence; and surface scattering by roughness. Optically transparent ceramics are often fabricated by either hot-isostatic pressing (HIP), or vacuum sintering at very high temperatures using ultrapure ultrafine powders. Combining the high sinterability of nanocrystalline (nc) powders with the rapid densification rates characteristic of spark plasma sintering (SPS) ${ }^{2}$, the latter technique has been widely promoted as a method for fabricating transparent polycrystalline oxides: transparent polycrystalline ceramics of various technical oxides, such as $\mathrm{Al}_{2} \mathrm{O}_{3}, \mathrm{MgO}, \mathrm{MgAl}_{2} \mathrm{O}_{4}$ spinel, mullite $\left(3 \mathrm{Al}_{2} \mathrm{O}_{3} \cdot 2 \mathrm{SiO}_{2}\right)$, YAG $\left(\mathrm{Y}_{3} \mathrm{Al}_{5} \mathrm{O}_{12}\right), \mathrm{Y}_{2} \mathrm{O}_{3}$ and Yttria-stabilized $\mathrm{ZrO}_{2}$ have been fabricated by SPS.

Bulk ceramic samples were produced by hot pressing process via sintering powders of the corresponding substances under pressure. The first remarkable preparations of optical ceramics for use as laser materials were carried out specifically with metal fluorides by Eastman Kodak ${ }^{3-5}$. This included the first hot-pressed polycrystalline $\mathrm{Dy}^{2+}: \mathrm{CaF}_{2}$ laser body. These fluoride samples exhibited sustaining lasing in them, but power of the generated beams $(7 \mathrm{~mW})$ was much lower than produced with single crystal laser bodies. Similar results were obtained with the use of oxide laser ceramic materials ${ }^{6,7}$. A new phase of laser ceramics development begins at the end of the $20^{\text {th }}$ to the beginning of the $21^{\text {st }}$ centuries, when the high quality neodymium-doped yttriumaluminum garnet ceramic materials were prepared ${ }^{8,9}$. In contrast with preceding experiments of the 1970s, the lasing properties of these products were comparable or superior to single crystals.

Recently techniques such as hot isostatic pressing, vacuum sintering, microwave sintering either solely or in conjunction with techniques such as slip casting, tape casting, texturation or electric/ magnetic field orientation is used in fabrication of transparent ceramics.

Since 2010, ICMCB has been actively involving in the fabrication of ceramics for a wide variety of applications such as piezoelectric, thermoelectric, batteries, bioceramics and optical applications. In this article, various applications of transparent ceramics and fabrication procedure of a cubic and non-cubic crystalline structure material as transparent ceramic with an example will be discussed.

\section{EXPERIMENTAL PROCEDURE}

In the present article, as we dealt with the fabrication of transparent ceramics by spark plasma sintering (SPS), the general procedure used for fabrication of transparent ceramics by SPS in the present work is presented below. For each experiment $1 \mathrm{~g}$ of nanopowder of the densifying material was filled in the graphite die having an inner diameter of $10 \mathrm{~mm}$. The graphite die was covered with a thermal insulator carbon fiber to avoid contamination from the graphite die to the starting powder. An optical pyrometer was used to measure temperature on the graphite die surface. The graphite mould was placed in SPS operating chamber (DR. SINTER LAB Spark Plasma Sintering system, Model SPS-511S / SPS-515S) under Vacuum of $10^{-6}$ Torr (10Pa). The pulse sequence for SPS applied voltage for all the samples was 12:2 (i.e. $12 \mathrm{ON} / 2 \mathrm{OFF}$ ). The shrinkage of the densifying powder was continuously monitored by the displacement of the punch rod. The temperature was first increased to $600^{\circ} \mathrm{C}$ within 3 minutes and then increased to a sintering temperatures with different heating rate $\left(\mathrm{R}_{\mathrm{H}}\right)$ ranging from $2^{\circ} \mathrm{C} /$ minute $-200^{\circ} \mathrm{C} /$ minute and dwell time. Uniaxial pressures ranging from $40 \mathrm{MPa}$ to $100 \mathrm{MPa}$ were applied at room temperature $\left(T_{R}\right)$ or at sintering temperatures $\left(T_{S}\right)$ depending on the hardness of the material 
densified. The cooling rate $\left(\mathrm{R}_{\mathrm{C}}\right)$ and $\mathrm{R}_{\mathrm{H}}$ were maintained equal in all the experiments. The higher value of $R_{H}$ and higher value of $R_{C}$ lead to opacity and cracking in ceramics. Usually the SPS densified ceramics are prone to coloration due to the reducing nature of SPS experimental process (which could also arise from porosity). After sintering, the thermal insulator layer on the ceramics was removed and the ceramics were annealed in air (this step is optional, depending on the sintering conditions employed) to compensate the lost oxygen in SPS chamber. Then the ceramics were mirror polished on both sides using diamond slurry. The thickness of the ceramics after polishing was approximately $2 \mathrm{~mm}$. Different characterization techniques are used followed by polishing of the sintered sample.

\section{RESULTS AND DISCUSSIONS}

Transparent ceramics are used for various applications ${ }^{10-17}$ with single crystals. In order to obtain transparent ceramics, the various vital parameters such as grain size, grain-boundary phase and pores has to be dealt with, in addition to various sintering parameters such as sintering temperature, sintering time, heating/ cooling rate, pressure application point and atmosphere of sintering. Here an example of the non-cubic material $\mathrm{Al}_{2} \mathrm{O}_{3}$ commonly called as polycrystalline alumina (PCA) transparent ceramics fabricated by SPS at ICMCB is given. The starting powders of $\alpha-\mathrm{Al}_{2} \mathrm{O}_{3}$ (Baikowski (BMA-15)) has a particle size of 100-150 mm. For the sake of comparison $\alpha-\mathrm{Al}_{2} \mathrm{O}_{3}$ of different makes $(99.99 \%$, average particle size: $0.4 \mu \mathrm{m}$, Ceralox, USA) was used as well to compare with BMA-15 powders. The various conditions that were used are given in table 1 and figure 1 shows the sample sintered at various sintering conditions. The behavior of the starting powders from different company were different at the same temperatures. As the starting powders are homogeneous and have high purity helps in avoiding the creation of scattering points, impurity segregation and has uniform grain growth. Transparent PCA can be fabricated by Spark Plasma Sintering without the addition of any dopant / pressures $>100 \mathrm{MPa}$. The grain growth can be restricted from a few nanometers to micrometers by optimizing the sintering temperature.

We have observed that the grain size increases with increase in sintering temperature. The grain size increases $>1 \mu \mathrm{m}$ for sintering temperatures $>1150^{\circ} \mathrm{C}$ even for the lower dwell duration $<5$ minutes. Above $1300^{\circ} \mathrm{C}$, the grain size increases progressively with the rapid increase of grain size to 2-3 $\mu \mathrm{m}$ for nanometric powder and reaches a maximum to $6 \mu \mathrm{m}$ for micrometric powder. In the present case, the best sintering temperature for obtaining the densification of PCA was $1150^{\circ} \mathrm{C}$ in conjunction with other sintering parameters to keep the grain growth optimal to have good optical and mechanical properties. A high in-line transmission of $65 \%$ and $85 \%$ were obtained in the visible and infra-red region respectively. The vital application related properties such as transmission, hardness, thermal diffusivity are strongly influenced by the sintering parameters. A detailed study on the various sintering parameters and their effective correlation has been studied. It is suggested that a heating and cooling rate of $100^{\circ} \mathrm{C} / \mathrm{min}$ at the sintering temperature of $1150^{\circ} \mathrm{C}$ for a dwell time of $1 \mathrm{~h}$ at $100 \mathrm{MPa}$ yielded highly densified samples. No post-annealing treatments are required for the improvement of transmission.

The application of pressure at the start and at only during the sintering time has a significant effect on densification. By applying the maximum pressure at dwell time/ high temperatures aids in better powder arranging because of easier particle sliding or rotation at high temperatures to eliminate voids. Further, with $\mathrm{P}_{\mathrm{S}}$ air trapped in the pores will be minimized and is possible to undergo the diffusion mechanism at the grain boundaries, aiding in the betterment of the transparency of the sample by retaining the grain size and porosity minimum. $P_{S}$ yields the best conditions for obtaining the transparent PCA with good mechanical strength. Pre-densified 
alumina compacts, did not attribute any significant changes in the transparency of the PCA ceramics. Formation of intergranular pores and intragranular pores can be controlled by the heating and cooling rates. At $\mathrm{T}_{\mathrm{s}}=1150^{\circ} \mathrm{C}$, the relative density increases with increasing dwell time. The density reaches maximum at $30 \mathrm{~min}$. The grain size increases with the increase of dwell time, reaching $0.3 \mu \mathrm{m}(15 \mathrm{~min})$ to $0.5 \mu \mathrm{m}(60 \mathrm{~min})$ for BMA-15. The grain size slightly increases when the dwell time $>60 \mathrm{~min}$. With dwell time $\sim 60-120 \mathrm{~min}$, the transparency of the sintered sample slightly decreases. The proportion of porosity in the sintered sample can be altered by increasing the dwell time. The overall improvement of physical properties of sintered transparent PCA increases with the increase in dwell time.

The Vickers hardness values obtained are rather high in comparison to other reported transparent PCA ceramics. The mechanical hardness obtained is in the range of $29.42 \mathrm{GPa} / 3000 \mathrm{Hv}$, due to the fine grain size of the ceramics. When the grain size increases, the thermal conductivity tends to increase and at higher temperatures, the thermal conductivity decreases due to the enhancement of phonon scattering. The shape and the orientation of the pore in the ceramics can also affect the thermal conductivity and according to its distribution could cause thermal conductivity anisotropy. In the present study, the pores formed in the ceramics don't correspond to any particular morphology. Photon thermal conductivity occurs due to porosity. High thermal conductivity of $21 \mathrm{Wm}^{-1} \mathrm{~K}^{-1}$ has been obtained for the fabricated PCA transparent ceramics, which could be possibly used in applications requiring high thermal dissipation.

10 at $\% \mathrm{Yb}^{3+}$ doped $\mathrm{Lu}_{2} \mathrm{O}_{3}$ (YLO) (cubic structured) transparent ceramics were obtained at $1700^{\circ} \mathrm{C}\left(\mathrm{t}_{\mathrm{s}}=5\right.$ minutes) at $100 \mathrm{MPa}$, with $\mathrm{R}_{\mathrm{H}}=50^{\circ} \mathrm{C} / \mathrm{Minute}$. The $\mathrm{SEM}$ micrographs in figure 2, shows that the dynamics of microstructure in YLO ceramics. We observed that the average grain size decreases with increasing $\mathrm{P}_{\mathrm{S}}$. Over the temperature range of $1400^{\circ} \mathrm{C}-1800^{\circ} \mathrm{C}$, with $\mathrm{P}_{\mathrm{S}}=100$ $\mathrm{MPa}, \mathrm{R}_{\mathrm{H}}=50^{\circ} \mathrm{C} /$ Minute and $\mathrm{t}_{\mathrm{s}}<20$ minutes, the grain grew uniformly, with distinct grain boundaries. Even under the aforesaid conditions except that under $t_{s}>20$ minutes yielded slightly lesser transmittance due to the significant abnormal grain growth. Irrespective of the temperatures used for sintering $>1400^{\circ} \mathrm{C}$, when $\mathrm{t}_{\mathrm{s}}>30$ minutes, the sintered samples cracks, as the average grain size increases over $20 \mathrm{~mm}$. The aforesaid results clearly indicate that the optical transmittance of the ceramics does not completely rely on grain size. In YLO ceramics, we observed that the formation of pore and increase of grain size is predominant at $\mathrm{R}_{\mathrm{H}}>50^{\circ} \mathrm{C} /$ minute and as well as at $\mathrm{R}_{\mathrm{H}}<50^{\circ} \mathrm{C} /$ minute, irrespective of $\mathrm{t}_{\mathrm{s}}$. The optimal $\mathrm{R}_{\mathrm{H}}$ to yield transparent YLO ceramics was determined to be $\mathrm{R}_{\mathrm{H}}=50^{\circ} \mathrm{C} /$ minute. A homogeneous microstructure was observed in the fabricated ceramics. The YLO ceramics had nearly 5-10\% improvement in transmittance upon post-annealing at $1200^{\circ} \mathrm{C}$ for $12 \mathrm{~h}$.

\section{CONCLUSION}

Brief discussions on the various available techniques and applications of transparent ceramics have been presented. The current state-of-art in sintering technology and nanopowder technology enables us to obtain device quality transparent ceramics. Various sintering parameters interplay in yielding the transparent ceramics. In order to achieve high transparency in the transparent ceramics, it is essential to control the microstructure to restrain the grain growth that is observed in ceramics densified at high temperatures. The surface properties and the inherent crystalline structure of the sintered body play a main role in determining the in-line transmittance. Further research on scaling effect to transfer the sintering parameters from the small dimensional samples to large dimensional samples is required to transfer to industrial applications. Various 
aspects on properties in comparison to single crystals with transparent ceramics shows its potential applications for devices. However further research is impending on porosity removal and grain orientation techniques to improve transparency similar to single crystals, where the mechanical properties shows an upper hand in transparent ceramics.

\section{REFERENCES}

${ }^{1}$ Jiang, D., Hulbert, D.M., Kuntz, J.D., Anselmi-Tamburini, U., Mukherjee, A.K., (2007) Spark plasma sintering: A high strain rate low temperature forming tool for ceramics,Mater. Sci. Eng. A Volume 463, 89-93.

${ }^{2}$ Wang S. W., Chen L. D., Hirai T., (2000) Densification of $\mathrm{Al}_{2} \mathrm{O}_{3}$ Powder Using Spark Plasma Sintering J. Mater. Res. Volume 15, 982-987.

${ }^{3}$ Carnall E, Hatch S E, Parsons W F. (1966) Optical studies on hot-pressed. polycrystalline $\mathrm{CaF}_{2}$ with clean grain boundaries Mater Sci Res. Volume 3, 165-173.

${ }^{4}$ Hatch, S.E.; Parson, W.F.; Weagley, R.J. (1964) Hot-pressed polycrystalline $\mathrm{CaF}_{2}: \mathrm{Dy}^{2+}$ laser Applied Physics Letters Volume 5 (8) 153-155.

${ }^{5}$ Carnall, E.; Hatch, S.E.; Parson, W.F.; Weagley, R.J. (1969) Hot-pressed polycrystalline laser materials US Patent Volume 3, 453,215-219.

${ }^{6}$ Greskovich C.and Chernoch J.P. (1973) Polycrystalline ceramic lasers J. Appl. Phys. Volume 44 (10) 4599-4606.

${ }^{7}$ Greskovich C and Chernoch J.P. (1974) Improved polycrystalline ceramic lasers J. Appl. Phys. Volume 45 (10) 4495-4502.

${ }^{8}$ Ikesue A, Kinoshita T, Kamata K, and Yoshida K, (1995) Fabrication and Optical Properties of High-

Performance Polycrystalline Nd:YAG Ceramics for Solid-State Lasers, J. Amer. Ceram. Soc. Volume 78, 1033-1040.

${ }^{9}$ Lu J., Ueda K,Yagi H, Yanagitani, T. Akiyama, Y. Kaminskii, A.A. (2002) Doped and undoped yttrium aluminium garnet (Y3A15O12) nanocrystalline ceramics-a new generation of solid state laser and optical materials, J. Alloy and Compounds Volume 341, 220-225.

${ }^{10}$ Ikesue A., Furusato I. (1995). Fabrication of polycrystalline transparent YAG ceramics by a solid-state reaction method. Journal of the American Ceramic Society, Volume 78, 1 225-228.

${ }^{11}$ Álvarez-Clemares I., Mata-Osoro G., Fernández A., López-Esteban S., Pecharromán C.,

Palomares J., Torrecillas R. \& Moya J.S. (2010). Transparent alumina/ceria nanocomposites by spark plasma sintering. Advanced Engineering Materials, Volume 12, 1154-1160.

${ }^{12}$ Appetz R. \& Van Bruggen M.P.B. (2003). Transparent alumina: a light scattering model. Journal of the American Ceramic Society, Volume 86, 3, 480-486

${ }^{13}$ Greskovich C. \& Chernoch J.P. (1973). Polycrystalline ceramic lasers. Journal of Applied Physics, Volume 44, 4599-4607.

${ }^{14}$ Hartnett T. M., Bernstein S. D., Maguire E. A., \& Tustison R. W. (1998). Optical properties of AlON (aluminum oxynitride). Infrared Physics \& Technology, Volume 39, 4, 203-211.

${ }^{15}$ Lu T. C., Chang X. H., Qi J. Q., Lu X. J., Wei Q. M., Zhu S., Sun K., Lian J. \& Wanga L. M. (2006). Low-temperature high-pressure preparation of transparent nanocrystalline $\mathrm{MgAl}_{2} \mathrm{O}_{4}$ ceramics. Applied Physics Letters, Volume 88, 21, 213120-213123

${ }^{16}$ Pecharroman C., Mata-Osoro G., Diaz L. A., Torrecillas R. \& Moya J. S. (2009). On the transparency of nanostructured alumina: Rayleigh-Gans model for anisotropic spheres, Optics Express Volume 17, 8, 6899-6912.

${ }^{17}$ Mouzon, J., Glowacki E. \& Odén M. (2008). Comparison between slip-casting and uniaxial pressing for the fabrication of translucent yttria ceramics. Journal of Material Science, Volume 43, 8, 2849-2856.

Table I. Various sintering conditions employed in present study

\begin{tabular}{|l|l|l|l|l|l|l|l|l|} 
Sample & Starting & $\mathbf{R}_{\mathbf{H}} / \mathbf{R}_{\mathbf{C}}$ & $\mathbf{T}_{\mathbf{S}}$ & $\mathbf{t}_{\mathbf{s}}$ & $\mathbf{P}_{\text {point }}$ & $\mathbf{P}_{\text {start }}$ & $\mathbf{P}_{\text {dwell }}$ & Grain \\
\hline
\end{tabular}




\begin{tabular}{|l|l|l|l|l|l|l|l|l|}
\hline code & powder & $\left.\mathbf{(}^{\mathbf{C}} \mathbf{C} \mathbf{m i n}\right)$ & $\left.\mathbf{(}^{\mathbf{0}} \mathbf{C}\right)$ & $\mathbf{( m i n )}$ & $\mathbf{( M P a})$ & $\mathbf{( M P a})$ & $\mathbf{( M P a )}$ & $\begin{array}{l}\text { Size } \\
(\boldsymbol{\mu m})\end{array}$ \\
\hline AL 6 & Micrometric & $100 / 100$ & 1400 & 0 & Initial & 100 & 100 & 1.5 \\
\hline AL 7 & Micrometric & $100 / 100$ & 1400 & 3 & dwell & 40 & 100 & 2 \\
\hline AL 8 & Nanometric & $100 / 100$ & 1400 & 3 & dwell & 40 & 100 & 1.5 \\
\hline AL 9 & Nanometric & $100 / 100$ & 1150 & 20 & dwell & 40 & 100 & 0.2 \\
\hline AL 10 & Nanometric & $8 / 8$ & 1150 & 15 & dwell & 40 & 100 & 0.1 \\
\hline AL 11 & Nanometric & $100 / 100$ & 1150 & 60 & dwell & 40 & 80 & 0.4 \\
\hline AL 12 & Nanometric & $100 / 100$ & 1150 & 60 & dwell & 40 & $80($ end $)$ & 0.1 \\
\hline AL 13 & Nanometric & $100 / 100$ & 1150 & 20 & dwell & 40 & 100 & 0.1 \\
\hline AL 14 & Nanometric & $100 / 100$ & 1150 & 60 & dwell & 40 & 100 & 0.4 \\
\hline AL 15 & Nanometric & $100 / 100$ & 1150 & 120 & dwell & 40 & 100 & 0.1 \\
\hline AL 17 & Nanometric & $50 / 50$ & 1150 & 60 & dwell & 40 & 100 & 0.2 \\
\hline AL 18 & Nanometric & $100 / 2$ & 1150 & 60 & dwell & 40 & 100 & 0.5 \\
\hline AL 19 & Nanometric & $100 / 100$ & 1150 & 30 & dwell & 40 & 100 & 0.3 \\
\hline AL 20 & Nanometric & $100 / 100$ & 1150 & 10 & dwell & 40 & 100 & 0.1 \\
\hline AL 21 & Nanometric & $100 / 100$ & 1150 & 30 & Initial & 100 & 100 & 1 \\
\hline AL 22 & Nanometric & $100 / 100$ & 1150 & 60 & Initial & 100 & 100 & 0.8 \\
\hline AL 23 & Nanometric & $100 / 100$ & 1200, & 1,30 & dwell & 40 & 100 & 0.5 \\
\hline AL 24 & Nanometric & $100 / 100$ & 1200, & 1,30 & dwell & 40 & 100 & 0.4 \\
\hline
\end{tabular}

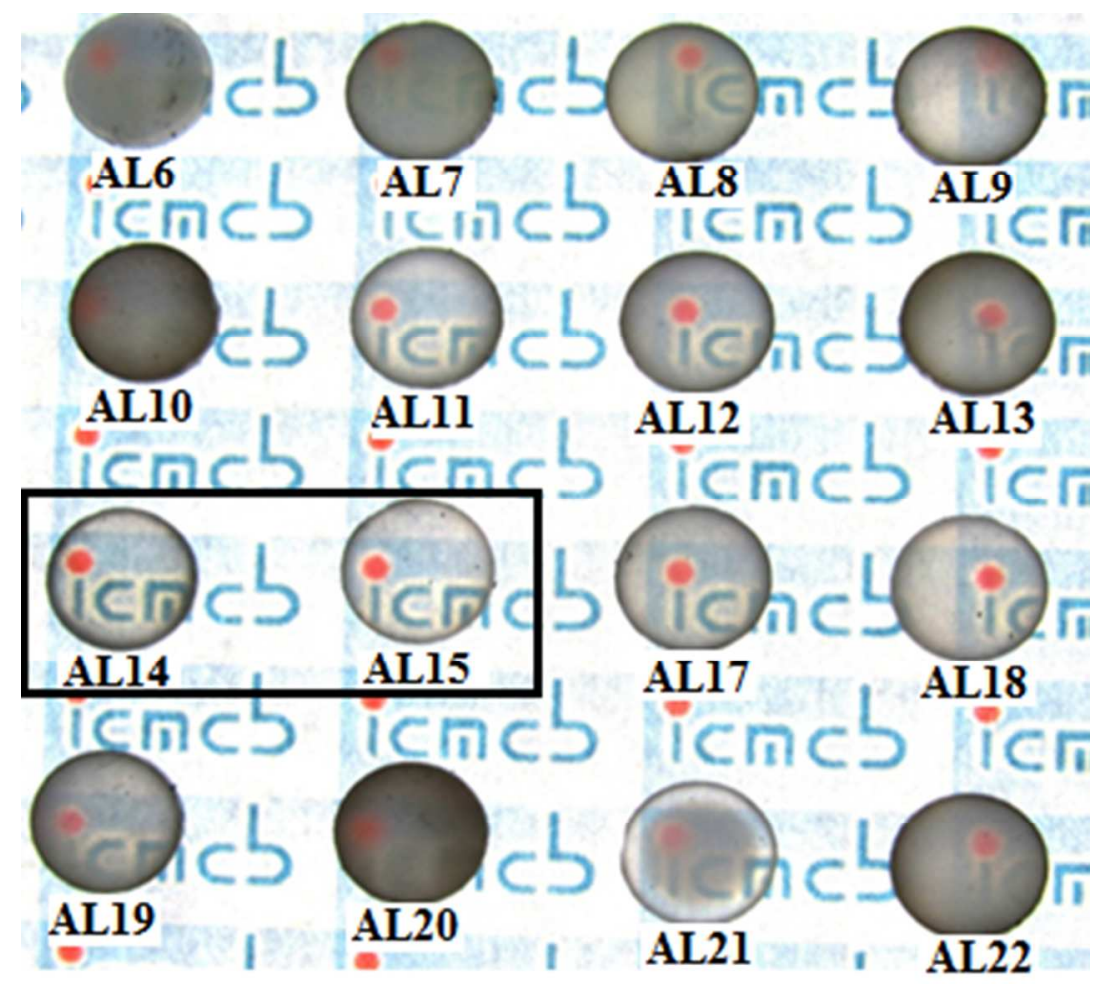


Figure1. Transparent PCA ceramics obtained with different sintering parameters (The encircled are the samples with best transparencies)
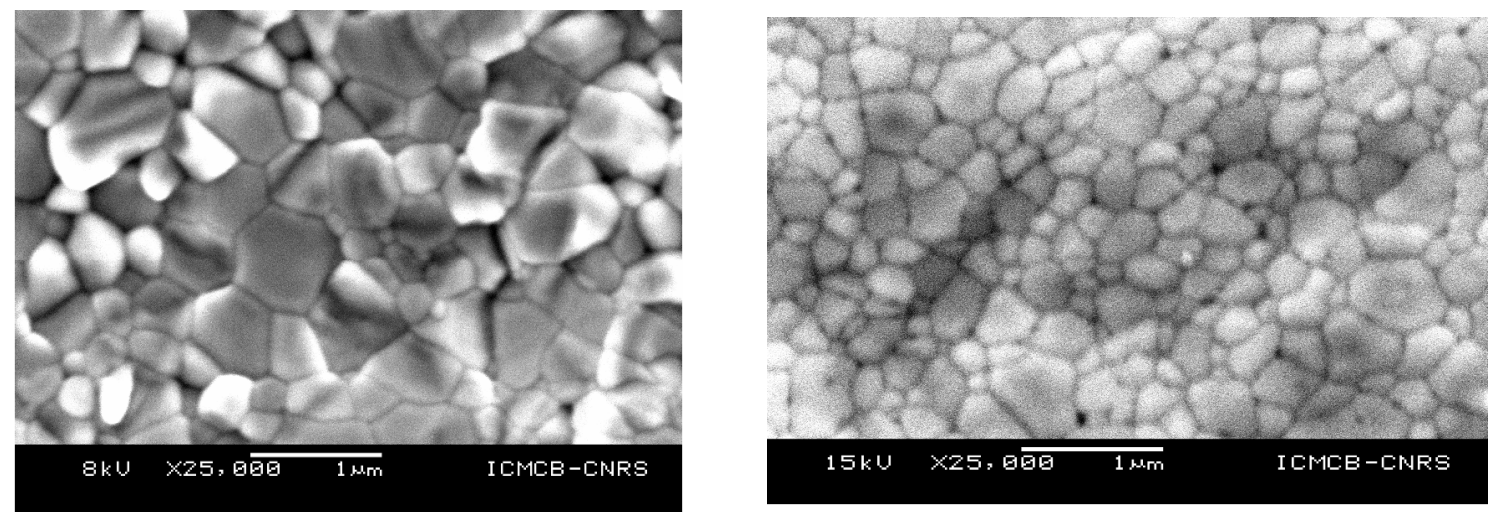

Fig (a) SEM micrographs of YLO ceramic (b) $500^{\circ} \mathrm{C}, 100 \mathrm{MPa}, \mathrm{t}_{\mathrm{s}}=5 \mathrm{~min}$ and $\mathrm{R}_{\mathrm{H}}=50^{\circ} \mathrm{C} /$ min, annealed at $1200^{\circ} \mathrm{C}$ for $12 \mathrm{~h}$ (b) $1700^{\circ} \mathrm{C}, 100 \mathrm{MPa}, \mathrm{t}_{\mathrm{s}}=5 \mathrm{~min}$ and $\mathrm{R}_{\mathrm{H}}=50^{\circ} \mathrm{C} / \mathrm{min}$, annealed at $1200^{\circ} \mathrm{C}$ for $12 \mathrm{~h}$ 